\title{
Determinants of Modern Contraceptive Methods (MCM) discontinuation among childbearing age women in Kinshasa, Democratic Republic of Congo.
}

Nathalie Pemba ( $\square$ nathaliekalpe2@gmail.com )

Kinshasa School of Public Health

Christophe Luhata

Kinshasa School of Public Health

Shahul H Ebrahim

University of Sciences, Technique and Technology, Bamako, Mali

Dalau Nkamba Mukadi

Kinshasa School of Public Health

Lise Lombeya

Minister of Health, National Reproductive Programme, DRC

Robert Colebunders

Global Health Institute, University of Antwerp, Antwerp, Belgium

John Ditekemena

Kinshasa School of Public Health

\section{Research Article}

Keywords: Modern Contraceptive Methods, discontinuation, women of childbearing age

Posted Date: February 26th, 2021

DOl: https://doi.org/10.21203/rs.3.rs-215312/v1

License: (c) (i) This work is licensed under a Creative Commons Attribution 4.0 International License. Read Full License 


\section{Abstract}

Background: Family planning (FP) is one of the main strategies to reduce maternal mortality in subSaharan Africa. However, only $8 \%$ of women use modern contraceptive methods in the Democratic Republic of Congo. It is estimated that at least $50 \%$ of women stop using Modern Contraceptive Methods (MCM) in sub-Saharan Africa. The objective of this study was to identify factors associated with MCM discontinuation in Kinshasa. Methods: A retrospective cohort study was conducted in Kinshasa from April through June 2019. Three hundred and eighty-seven women who attended 10 health facilities in 10 health zones of Kinshasa (one facility per health zone) were enrolled in the study. Predictors of modern contraceptive discontinuation were investigated, using Cox regression. Results: The proportion of MCM discontinuation was $21.4 \%$ (95\% Cl: $17.6-25.8) ; 60.2 \%$ for implants and $24.1 \%$ for contraceptive injections. Predictors for dicontinuation were: unemployement $(\mathrm{Hz} . \mathrm{R}=2.23 ; 95 \% \mathrm{Cl}: 1.35-3.70 ; \mathrm{p}=$ $0.003)$; having no or only one child $(\mathrm{Hz} . \mathrm{R}=2.89 ; 95 \% \mathrm{Cl}: 1.43-5.85 ; \mathrm{p}=0.015)$; using a short-acting method $(\mathrm{Hz} . \mathrm{R}=4.61 ; 95 \% \mathrm{Cl}: 2.81-7.56 ; \mathrm{p}<0.001)$; lack of sufficient explanations about MCM (Hz.R = 3.14; 95\% Cl: 1.93-5.11; $p<0.001)$ and side effects ( $\mathrm{Hz} . \mathrm{R}=2.93 ; 95 \% \mathrm{Cl}: 1.79-4.80 ; \mathrm{p}=0.001)$. Conclusion: MCM discontinuation was high among women in Kinshasa. While it is important to reinforce strategies to increase MCM uptake, it is also critical to increase its continuation.

\section{Background}

According to the United Nations World Fertility and Family Planning 2020 report, the use of contraceptives reduced high risk pregnancies as well as maternal and infant mortality in 2019. Family planning (FP has the potential to avert approximately $30 \%$ of maternal and $10 \%$ of child deaths (1). Contraception remains one of the main strategies to reduce maternal mortality. Castle $S$ and al 2015 reported that the use of Modern Contraceptive Methods (MCM) by 309 million women in 69 Family Planning (FP) 2020 initiative targeted countries prevented about 84 million unwanted pregnancies, 26 million unsafe abortions and 125,000 deaths in mothers (2). Contraception therefore saves the lives of nearly 250,000 women worldwide each year and could save 100,000 more if most women used MCM; it prevents more than $30 \%$ of maternal deaths and more than $10 \%$ of infant deaths (3-5). Half of all unintended pregnancies in developing countries are terminated, mostly in illegal or dangerous circumstances, which can lead to death (6). Moreover, currently it was estimated that contraceptive use in sub-Saharan Africa prevents $22 \%$ of HIV-positive births (7). Stopping contraceptive use remains a major challenge, particularly in sub-Saharan Africa. Jain et al, estimated that $38 \%$ of women using family planning, stopped using MCM. This attrition rate increased to reach more than $50 \%$ in 16 in sub-Saharan Africa countries in 2017 (9).

The Democratic Republic of Congo (DRC) was among the countries with the highest maternal mortality rates in the world in 2015 and was among the six countries that contributed to half of the maternal and infant mortality in the world. Its fertility rate and proportion of contraceptive use were respectively of 5,8 and 22,4\% in 2019 (1). According to Demographic Health Survey (DHS) data in 2014 more than 80\% of all men and women in the DRC knew at least one contraceptive method, and $24 \%$ of women who did not use 
any contraceptive method, expressed an unmet need for FP (14). The aim of this study was to determine the magnitude of MCM discontinuation and identify factors associated with discontinuation in Kinshasa.

\section{Methods}

\section{Study setting}

Kinshasa representing the highest contraceptive prevalence with $19 \%(14)$, is the capital city of the DRC with a multi-ethnic population estimated at around 12 million inhabitants and it includes 35 Health Zones. Out of the 876 health facilities, 428 offer the FP package and are distributed in all 35 health zones. Ten health facilities were selected by reasoned and convenience choice, each located in a different health Zone were included in the study. Accessible facilities in the FP network were prioritized for inclusion in the study. All health facilities were secondary level general referral hospitals, among them four were public, two faith based and four private hospitals.

\section{Study design and inclusion criteria}

A retrospective cohort study was carried out from February through May 2019. The first step consisted of a review of registers and client' charts in health facilities to select women on MCM according to the study criteria. This step was followed by data abstraction using a data collection tool. To collect missing data, clients were also traced and interviewed in the community. Study participants were selected women of reproductive age (18-49 years) having used MCM for a period ranging from 3 months to 5 years from facilities offering FP services, located in urban and urban-rural areas.

Data were collected from 387 women aged 18-49 years in the city of Kinshasa, followed during the period from 2014-2018 and having used MCM at least 3 months before data collection (Fig 1).

\section{Data collection}

A team of experienced investigators was recruited and trained. They worked with the health providers and affiliated community health workers (CHW) of the selected health facilities.

These health providers offer health services at the facility level including FP services and collect data using specific routine data collection tools. The CHWs used text messages, phones calls and home visits streamline the pateints' monitoring and if needed to collect follow up information.

Data collection took place from February - May, 2019. Client charts, registers and data collection tools of CHWs were used to abstract the needed information related to the selected clients. The study staff used a structured questionnaire for data abtraction. In addition, the most missing information was collected by using simple data collection tool based the needs.

Data processing and analysisDuring data collection, data quality control was performed to ensure completeness, accuracy and reliability of the data. Responses were also checked to correct 
inconsistencies. The data were keyed using the EPIDATA 3.1 software and analyzed with SPSS version 23 (Statistical Package for Social Sciences) and R software. Frequency and proportion measures were used to summarize the categorical variables; means and standard deviations (SD) or medians and interquartile range to summarize continuous variables. The categorical variables were presented as absolute and relative frequencies. Missing data were imputed by the mean for continuous variables such as age, and by the predominant category for categorical variables such as parity or occupation.

We used Kaplan-Meier methods to estimate the probability of discontinuation stratified by experience of side effects, by type of MCM (short-acting vs long acting), and by pre-MCM counselling, with a log-rank test to assess differences in discontinuation rates. Cox proportional risk models were used to assess factors associated with MCM discontinuation. Likelyhood ratio was used to identify potential variables to include in the multivariable model and proceeded with the backward stepwise elimination. The variable's association was assessed using the crude and adjusted Hazard ratios (Hz.R). Statistical significance was assessed using the $95 \%$ confidence intervals $(\mathrm{Cl})$ and $\mathrm{p}$-value $<0.05$.

\section{Results}

The mean age was 30 years (SD: 7.12), 77.8\% of women were between 25 and 49 years. The median parity was 3 (IQR: 2), 59.7\% had 2-4 children; $60.2 \%$ were officially maried, $26.4 \%$ were living together with a sexual partner, $86.8 \%$ had only one sexual partner and most women (86.8\%) had a primary or secondary educational level (Table 1)Eighty three women $(21.4 \% ; 95 \% \mathrm{Cl}: 17.6-25.8)$ discontinued MCM. Most discontinued methods were implants in 50 (60.2\%) and contraceptive injections in 20 (24.1\%).Reasons for MCM discontinuation cited by participants were: side effects, expiration of time to use the method, desire of pregnancy, poor perception/misconceptions and unexpected pregnancy. No removal of implants was reported. (Table 2)Two hundred twenty two (57.4\%) reported side effects, 172 (44.4\%) of them continued to use the MCM. Among the 47 women who discontinued MCM for side effect, the main cited side effects were: amenorrhea, vaginal bleeding, dizziness, headache, weight gain. In multivariable analysis, MCM discontinuation was associated with - unemployment; -lower parity; - shortacting MCM; -lack of effective FP counseling; - and side effects (Table 3). Figures 2-5 show the KaplanMeier curves of participants continuing MCM, according to type of methods, side effects and poor preMCM counseling.

\section{Discussion}

Our results show that two out of ten women discontinued MCM. Implants and contraceptive injection were the methods most frequently discontinued. Side effects, product expiration and desire for pregnancy were the main reasons for giving up MCM. Short-acting methods, lack of informed explanation before using MCM, side effects, lower parity and unemployment were factors associated with discontinuation of MCM use. 
The main reasons for discontinuation cited by women were side effects (59\%), expiration of the the product (mostly for the implant) $(14.5 \%)$, desire for pregnancy $(13.3 \%)$ and poor perception of MCM $(9.6 \%)$. Several studies have reported side effects as the main reason for discontiuation $(13 ; 24 ; 27 ; 48 ; 51 ; 52)$.

Our result showed a higher implant discontinuation rate (60.2\%) compared to many other studies. For example, Barden et al,2018; Rachidul et al, 2015 and Njoku et al, 2014 reported $6.3 \% ; 0.72 \%$ and $11 \%$ as implant discontinuation respectively $(11 ; 13 ; 24 ; 27 ; 50 ; 51)$.

Many women in our study with an implant (67\%) reported side effects, mainly menstrual disorders. The lack of optimal FP counseling about potential side effects, prior to insertion, can negatively influence the retention of the implant $(56 ; 57)$.

Similar to other studies, the desire to become pregnant was also an important reason for discontinuation $(54 ; 55)$. Product (MCM) expiration was reported as the second main reason for withdrawal. However, this was only reported by women with an implant. This could be due to insufficient follow up of women on MCM as well as poor pre-MCM counseling. Clients' follow-up offers the possibility for additional advice and early management of possible side effects. Improved monitoring of MCM use will ensure the success of the FP strategy (55).

Five factors were significantly associated with the discontinuation of MCM (Table 4). Women who used short-acting MCM were more likely to discontinue than those who were on long-acting MCM. A similar result was found by Sara Casey et al. in North Kivu and Simmons $R$ et al. in the USA $(13,52)$. This association could be due to the fact that stopping short-term MCM, in contrast with long-acting MCMs, does not require provider's assistance (27). In addition, contraceptive injections and oral contraceptive, may produce side effects leading to discontinuation (13) as also reported by .Nigisti B et al. in northern Ethiopia (49).

Similar to the Ethiopian study, women who did not receive sufficient explanations about MCM were more likely to abandon MCM. Improving the quality of contraceptive counseling is one of the strategies to reduce contraceptive discontinuation and unwanted pregnancies (49). Women who use MCMs with no or only one child were more likely to abandon the method than those who had more children as was also reported in many other studies $(24,50,53)$. Unemployed women were more likely to abandon MCM than those with a profession as was also previously reported (32;33). Women with a profession are likely to have a higher level of education, allowing them to have more access to FP services and information. Moreover they more likely to want to keep their job than to have an unwanted pregnancy. Our study has some limitations. In our retrospective study, in some medical charts information such as client age, profession and parity and follow up information was missing. All missing data were imputed by the mean for quantitative variable, or the mode for qualitative variables. During the interviews in the community may be responses were influenced by social desirability. 


\section{Conclusion}

This study found a significant level of discontinuation of MCM among women in the city of Kinshasa. The use of short-acting MCM, side effects, lack of sufficient explanations about MCM before the use of MCMs, having no or only one child and unemployment were identified as the main predictors of discontinuation of MCMs. There is a need to streamline FP strategy by strengthening the MCM counseling and improving the follow up of clients using MCM.

\section{Declarations}

\section{Ethics approval and consent to participate}

The study protocol was approved by the Institutional Review Board (IRB) of the Kinshasa School of Public Health (NESP/DIR/MK/048/MM/2019), as well as the administrative authorities offices of the Health Zone. All methods were performed in accordance with the relevant guidelines and regulations (Declaration of Helsinki ). All study participants were 18 years old and over and those who were interviewed provided a written informed consent. The informed consent statement, included important and relevant information of the study.To ensure confidentiality, the data were collected anonymously and only available to the study investigators. The study team was bound by professional secrecy with regard to all the information collected. The data collection cards are kept secured by the principal investigator until the required time before their total destruction.

\section{Consent for publication}

Not applicable

\section{Availability of data and material}

The datasets used during the current study are available from the corresponding author on reasonable request.

\section{Competing interests}

The authors declare that they have no competing interests.

\section{Funding}

This study was carried out with funding provided by the United States Agency for International Development (USAID). USAID did not have any role in study design, data collection, and analysis, manuscript development or decision to publish.

\section{Authors' contributions}


Conceptualization, NP, CL and JD; formal analysis, CL, NP and JD; funding acquisition, NP and JD; methodology, NP, JD, DNM and CL; project administration, NP; supervision, JD; writing-original draft, NP and JD; writing-review, editing, and revisions, NP, JD, RC, CL, DNM, LL and SHE. All authors have read and agreed to the published version of the manuscript.

\section{Acknowledgment}

We are thankful to the USAID for funding the MPH program for Nathalie PEMBA.

This funding source is non-commercial.

\section{Abbreviations}

CHWs: Community Health Workers; Cl: confidence interval; DHS: Demographic and Health Survey; DRC:

Democratic Republic of Congo; FP: Family Planning; IQR: interquartile range; MCM: Modern Contraceptive Method; SD: Standard deviation; SPSS: Statistical package for social sciences.

\section{References}

1. United Nations, Department of Economic and Social Affairs. World Fertility and Family Planning 2020. UN, New York, 2020. https://www.unpopulation.org /

2. Castle S, Askew I. Contraceptive discontinuation: Reasons, challenges and solutions. Population Council, New York, 2015.

3. Ali MM, Cleland J, Shah IH. Causes and consequences of contraceptive discontinuation: evidence from 60 demographic and health surveys, Geneva: WHO, 2012.

4. Rutstein S. Effects of preceding birth intervals on neonatal, infant and under-five years' mortality and nutritional status in developing countries: evidence from the Demographic and Health Surveys, International Journal of Gynecology \& Obstetrics, vol 89, April 2005.

5. Cleland J., Shah I. and Benova L. A fresh look at the level of unmet need for family planning in the postpartum period, its causes and program implications, International Perspectives on Sexual and Reproductive Health, vol 41, 2015.

6. Sedgh S., Singh S. and Hussein R. Intended and unintended pregnancies worldwide in 2012 and recent trends, Studies in Family Planning, 2014.

7. Reynolds HW, Steiner MJ and Cates JW. Contraception's proved potential to fight HIV. Sex Transm Infect, 2005.

8. Fonds des Nations Unies pour la Population. Les contraceptifs sauvent des vies, 2012.

9. Jain A., Winfrey W. Contribution de l'arrêt de la contraception aux naissances non intentionnelles dans 36 pays en développement, Stud Fam Plan, 2017.

10. Jain A. Relative effectiveness of contraceptive methods during postpartum period, IUSSP Scientific Panel on Reproductive Health, Cochin, India, November 2014. 
11. Barden-O'Fallon J, llene S, Calhoun L. Interruption de la contraception chez les femmes et changement de comportement en milieu urbain au Sénégal, 2010-2015, BMC, 2018.

12. Bradley S., Schwandt H., Khan S. Levels, trends and reasons for contraceptive discontinuation. Calverton, MD: ICF Macro, 2009.

13. Casey S., Cannon A., Mushagalusa BB, Muyisa JB et al. Twelve-month contraceptive continuation among women initiating short- and long acting reversible contraceptives in North Kivu, Democratic Republic of the Congo. Plos one 2017.

14. Demographic Health Survey. DRC, 2014

15. Global Consensus Statement: Expanding Contraceptive Choice for Adolescents and Youth to Include Long-Acting Reversible Contraception, 2015.

16. Blanc K., Ali M., Tsui A et al. Patterns and Trends in Adolescents' contraceptive use and discontinuation in developing countries and comparisons with adult women. International Perspectives on Sexual and Reproductive Health. 2009

17. Kaushalendra K., Brijesh P. Contraceptive discontinuation and switching patterns in Bangladesh, Genus, 2011.

18. Nancy Yinger. La Jeunesse et les méthodes contraceptives réversibles et à longue durée d'action, Septembre 2016.

19. Blanc K., Curtis S., Croft T. Monitoring contraceptive continuation: Links to fertility outcomes and quality of care. Studies in Family Planning. 2002;

20. Darroch J.E, Audam S., Biddlecom A. et al. Adding it up: The Ccsts and benefits of investing in sexual and reproductive health, New York: Guttmacher institute, 2017

21. Catherine d'Arcangues, Médecine de la Reproduction, Gynécologie Endocrinologie, vol. 11, n 5 , Génève, 2009

22. Ali M. and Cleland J. Reproductive consequences of contraceptive failure in 19 developing countries, Obstetrics \& Gynecology, 2004.

23. Alvergne A., Stevens R. and Gurmu E. Side effects and the need for secrecy: characterising discontinuation of modern contraception and its causes in Ethiopia using mixed methods. Contraception and Reproductive Medicine, 2017.

24. Kiran A., Sanjay K. and Rajesh K. Socio-economic differentials in contraceptive discontinuation in India, Sage Open, April-June 2016.

25. Berlan E., Mizraji K., Bonny AE. Twelve-month discontinuation of etonogestrel implant in an outpatient pediatric setting. 2014.

26. Chiles D., Roberts A., Klein A. Initiation and continuation of long-acting reversible contraception in the United States military healthcare system. Society for Adolescent Health and Medicine, 2016.

27. Yideta Z., Mekonen L, Seifu W and Shine S. Contraceptive discontinuation, method switching and associated factors among reproductive age women in Jimma Town, Southwest Ethiopia. Fam Med, 2017. 
28. Melese S. et al. Implanon discontinuation rate and associated factors among women who ever used Implanon in the last three years in Debre Markos Town, ARC Journal of Public Health and Community Medicine Volume 2, 2017.

29. Danielle M., Bateson D., Frearson M. et al. Current barriers and potential strategies to increase the use of long- acting reversible contraception (LARC), Australia 2017.

30. Staveteig S., Mallick L., Winter R. Uptake and discontinuation of long-acting reversible contraceptives (LARCs) in low-income countries. DHS analytical studies No. 54, septembre 2015.

31. Mahesh P., Corinne H. Roccab. Contraceptive discontinuation and pregnancy postabortion in Nepal: a longitudinal cohort study. 2014.

32. Tina R, Foster-Rosales A, Ushma D.et al. One-year contraceptive continuation and pregnancy in adolescent girls and women initiating hormonal contraceptives, Obstet Gynecol, February 2011.

33. Shah N. et al. Reasons and correlates of contraceptive discontinuation in Kuwait, Contracept Reprod Health Care, 2007.

34. Haddad L., Wall K., Walika B. et al. Contraceptive discontinuation and switching among couples receiving integrated HIV and family planning services in Lusaka, AIDS, Zambia, October 2013.

35. Mukengeshayi N., Ngalula R, Malonga F et al. Utilisation des méthodes contraceptives modernes en République Démocratique du Congo : prévalence et barrières dans la zone de santé de Dibindi, Pan African medical journal, 2017

36. Mekonnen A. et al. Factors affecting continuity and success of community-based reproductive health service programme in rural community of Northeast Ethiopia, East Afr Med J. 2008.

37. Kibira S, Muhumuza C, Bukenya $J$ et al. A qualitative study of experiences of women using modern contraception in Wakiso District, PLOS ONE, Uganda, 2015.

38. The Future Institute. The impact of stockouts on the use of modern contraception, 2013.

39. Hubacher D., Olawo A., Manduku C. et al. preventing unintended pregnancy among young women in Kenya: prospective cohort study to offer contraceptive implants, Contraception, November 2012.

40. Hytell M., Rasanathan J., Tellier M. and al. Use of injectable hormonal contraceptives, Reproductive Health Matters, vol 20, Uganda, 2012.

41. Fruzzetti F., Perini D., Fornaciari L. et al. Discontinuation of modern hormonal contraceptives: an Italian survey. European journal of contraception \& reproductive health care, volume 21, 2016.

42. Sznajder K., Tomaszewski K., Burke A. and al. Incidence of discontinuation of long-acting reversible contraception among adolescent and young adult women served by an urban, Primary Care Clinic, $\mathrm{J}$ Pediatr Adolesc Gynecol. February 2017.

43. Imbuki K. et al. Factors influencing contraceptive choice and discontinuation among HIV-positive women in Kericho, Afr J Reprod Health, Kenya, 2010.

44. Gbagbo Y. and Esinam A. Use and discontinuation of intrauterine contraceptive device in the Greater Accra Region of Ghana. Contraception and Reproductive Medicine, 2018. 
45. Ochako R., Mwende S., Kaimenvi S, et al. Barriers to modern contraceptive methods uptake among young women in Kenya: a qualitative study. Biomed Central, 2015.

46. Jacobstein, R. and Polis C. Progestin-only contraception: Contraceptive injection and implants, Best Practice and Research in Clinical Obstetrics and Gynaecology, 2014.

47. Nandini A., Dasgupta Z., Zaba B. and al. Contraceptive dynamics in rural northern Malawi: A prospective longitudinal study. Int Perspect Sex Reprod Health. 2015.

48. Bekele T, Gebremariam A, Tura P. Factors associated with contraceptive discontinuation in Agarfa District, South east Ethiopia. Epidemiology sunnyvale, Vol.5, 2015.

49. Nigisti B., zemene A., Hadgay H. and al. Prevalence and factors associated with modern contraceptive discontinuation among reproductive age group women, a community based cross sectional-study in humera Town, northern Ethiopia, BMC women's health, vol.18, 2018.

50. Rashidul A., Golam H., Razzaque A. and al. Prevalence and associated factors of contraceptive discontinuation and switching among bangladeshi married women of reproductive age. Open access journal of contraception, 2015.

51. Njoku C., Emechebe C., Agbarakweh et al. Utilization and discontinuation of contraceptive methods, the University of Calabar Teaching Hospital experience, GJMEDPH, vol.3, 2014.

52. Simmons R, Sanders J, Geist $C$ and al. Predictors of contraceptive switching and discontinuation with the first six month of use among HER salt Lake study participant, AJOG, 2018.

53. Farwa R.and Ghazia I. Reasons for discontinuation of contraceptive methods among couples with different family size and educational status, JAMC, 2012.

54. Kibrom T.W et al, Reasons and multilevel factors associated with unscheduled contraceptive use discontinuation in Ethiopia, BMC, 2019.

55. Mengstu M.A. et al, Early Implanon Discontinuation and Associated Factors among Implanon User Women in Debre Tabor Town, Ethiopia, International Journal of Reproductive Medicine, 2018.

56. Abreham N. and Achamyelesh G, Discontinuation rate of Implanon and its associated factors among women who ever used Implanon in Dale District, BMC, 2018.

57. Gustiana Rina, Factors Associated with Contraceptive Discontinuation in

58. Indonesia, 2010.

59. Nirali M. et al, Quality of Contraceptive Counseling and Method Continuation in Pakistan and Uganda, Global health: Science and Practice, 2019, Vol 7.

\section{Tables}

Table 1: Women's socio-demographic characteristics (1) 
Age (years)

Mean(SD)

$18-24$

86

$30.56(7.12)$

25-34

188

22.2

$35-49$

113

48.6

29.2

Marital status

Single

41

10.6

Maried

233

60.2

Living without maried

102

26.4

Separated / Divorced

11

2.8

Number of sexual partners

\begin{tabular}{lcc} 
None & 10 & 2.6 \\
Only one & 252 & 65.1 \\
One but not married & 84 & 21.7 \\
Multiple partners & 41 & 10.6 \\
Age of partner (years) & & \\
$<35$ years & 89 & 26.5 \\
35-44 years & 114 & 34.0 \\
$45-54$ years & 52 & 15.2 \\
$\geq 55$ years & 81 & 24.1 \\
Occupation of partner & & \\
Public official & 64 & 19.3 \\
Private sector & 68 & 20.5 \\
Small jobs & 166 & 50.0 \\
\hline Driver & 34 & 10.2
\end{tabular}

Education level

Primary school

16

4.1 
Secondary school

College level
316

55

81.7

14.2

SD: Standard deviation; IQR: Interquartile range;

Table 1: Women's socio-demographic characteristics (2)

\begin{tabular}{lcc}
\hline Variables & $\begin{array}{c}\text { Frequency } \\
(\mathrm{n}=387)\end{array}$ & $\begin{array}{c}\text { Percentage } \\
\text { (\%) }\end{array}$ \\
\hline Profession & 111 & 28.7 \\
\hline Unemployed & 41 & 10.6 \\
\hline Public official & 178 & 46.0 \\
Small jobs & 57 & 14.7 \\
\hline Shop keeper & & \\
\hline Parity & & $3(2)$ \\
\hline Median(IQR) & 62 & 16.0 \\
\hline $0-1$ children & 231 & 59.7 \\
\hline 2-4 children & 94 & 24.3 \\
\hline 5 children & & \\
\hline
\end{tabular}

Table 2: Main type of MCM discontinued by women 


\begin{tabular}{lll}
\hline Type of MCM & Frequency (n) & Percentage (\%) \\
\hline Contraceptive Implant, n (\%) & 50 & 60.2 \\
\hline Contraceptive injection, n (\%) & 20 & 24.1 \\
\hline Oral contraceptive (Pill), n (\%) & 11 & 13.3 \\
\hline Intrauterine Device (IDU), n (\%) & 1 & 1.2 \\
\hline Contraceptive Ring, n (\%) & 1 & 1.2 \\
\hline Total & $\mathbf{8 3}$ & 100 \\
\hline
\end{tabular}

Table 3: Main reasons mentioned for MCM discontinuation

\begin{tabular}{|c|c|c|}
\hline Reasons & Frequency $\left(n=83^{*}\right)$ & Percentage (\%) \\
\hline \multicolumn{3}{|l|}{ Side effects } \\
\hline No & 36 & 43.4 \\
\hline Yes & 47 & 56.6 \\
\hline \multicolumn{3}{|l|}{ Product expiration } \\
\hline No & 71 & 85.5 \\
\hline Yes & 12 & 14.5 \\
\hline \multicolumn{3}{|l|}{ Desire of pregnancy } \\
\hline No & 72 & 86.7 \\
\hline Yes & 11 & 13.3 \\
\hline \multicolumn{3}{|l|}{ Rumors } \\
\hline No & 75 & 90.4 \\
\hline Yes & 8 & 9.6 \\
\hline \multicolumn{3}{|l|}{ MCM faillure } \\
\hline No & 77 & 92.8 \\
\hline Yes & 6 & 7.2 \\
\hline \multicolumn{3}{|l|}{ Advices from relatives } \\
\hline No & 77 & 92.8 \\
\hline Yes & 6 & 7.2 \\
\hline \multicolumn{3}{|l|}{ Husband's order } \\
\hline No & 80 & 96.4 \\
\hline Yes & 3 & 3.6 \\
\hline
\end{tabular}

*Number of times reasons were mentioned by the 47 women who discontinued MCM. A woman could mention more than one reason. 
Table 4: Factors associated with MCM discontinuation in women

\begin{tabular}{llllll}
\hline Factors & Frequency & Hz.R. & IC 95\% Hz.R & Hz.R. & IC 95\% Hz.R p-value
\end{tabular}
crude crude adjusted adjusted

Effective counseling

$\begin{array}{ccccccc}\text { Yes } & 285 & 1 & & & & \\ \text { No } & 102 & 3.82 & 2.47-5.89 & 3.14 & 1.93-5.11 & <0.001\end{array}$

Profession of women

$\begin{array}{rcccccc}\text { employed } & 276 & 1 & & & & \\ \text { Unemployed } & 111 & 1.98 & 1.25-3.15 & 2.23 & 1.35-3.70 & 0.003\end{array}$

Parity

$\begin{array}{lrccrrr}\geq 5 \text { children } & 94 & 1 & & & & \\ 0-1 \text { children } & 62 & 2.11 & 1.10-4.04 & 2.89 & 1.43-5.85 & 0.015 \\ 2-4 \text { children } & 231 & 1.12 & 0.67-1.86 & & & \end{array}$

Type of MCM

$\begin{array}{ccccccc}\text { Long term action } & 315 & 1 & & & & \\ \text { Short term action } & 72 & 4.69 & 2.96-7.43 & 4.61 & 2.81-7.56 & <0.001\end{array}$

\section{Awarness on MCM}

effectiveness

Not effective $\quad 29 \quad 1$

$\begin{array}{llll}\text { Effective } \quad 358 \quad 0.28 & 0.16-0.50\end{array}$

Side effects

$\begin{array}{cccccrr}\text { Yes } & 221 & 1.86 & 1,16-2,98 & 2,93 & 1,79-4,80 & 0,010 \\ \text { No } & 166 & 1 & & & & \end{array}$

Hz.R: Hazard ratio

MCM: Modern contraceptive method

\section{Figures}




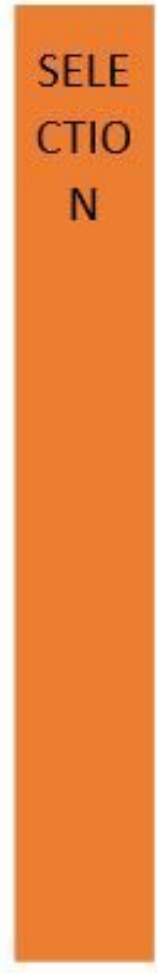

PART
ICIPA
TION
$\&$
ANAL

Figure 1

Consort Chart

$$
\begin{aligned}
& \text { Available files of women } \\
& \text { on MCM for the study } \\
& \qquad(n=471)
\end{aligned}
$$

- Files almost empty

$$
(\mathrm{n}=38)
$$

- Major information lacking $(\mathrm{n}=27)$

- Serious inconsistencies in the files $(\boldsymbol{n}=\mathbf{1 0})$

- Less than 18 years old ( $\boldsymbol{n}=$ 9)

Included in the analyse

$$
(n=387)
$$




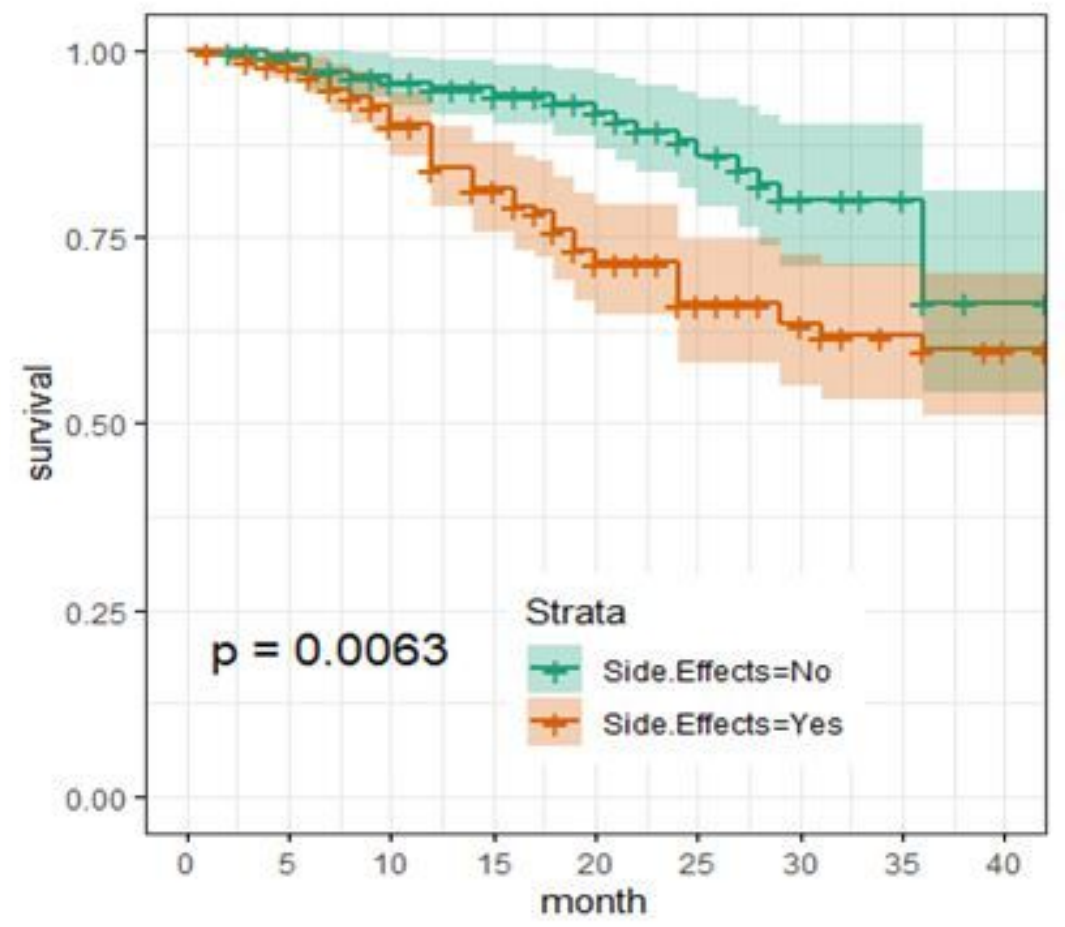

Figure 2

MCM drop out by side effects

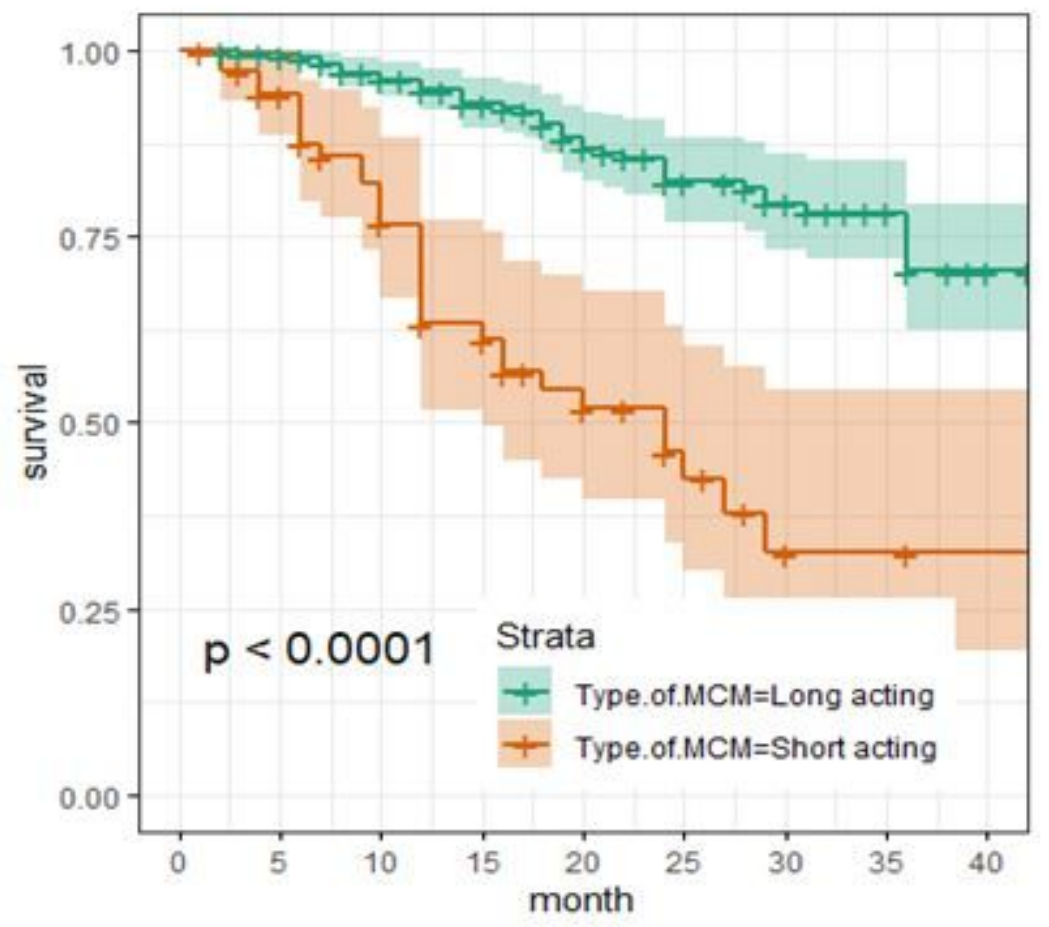

Figure 3

MCM drop out by MCM ty 


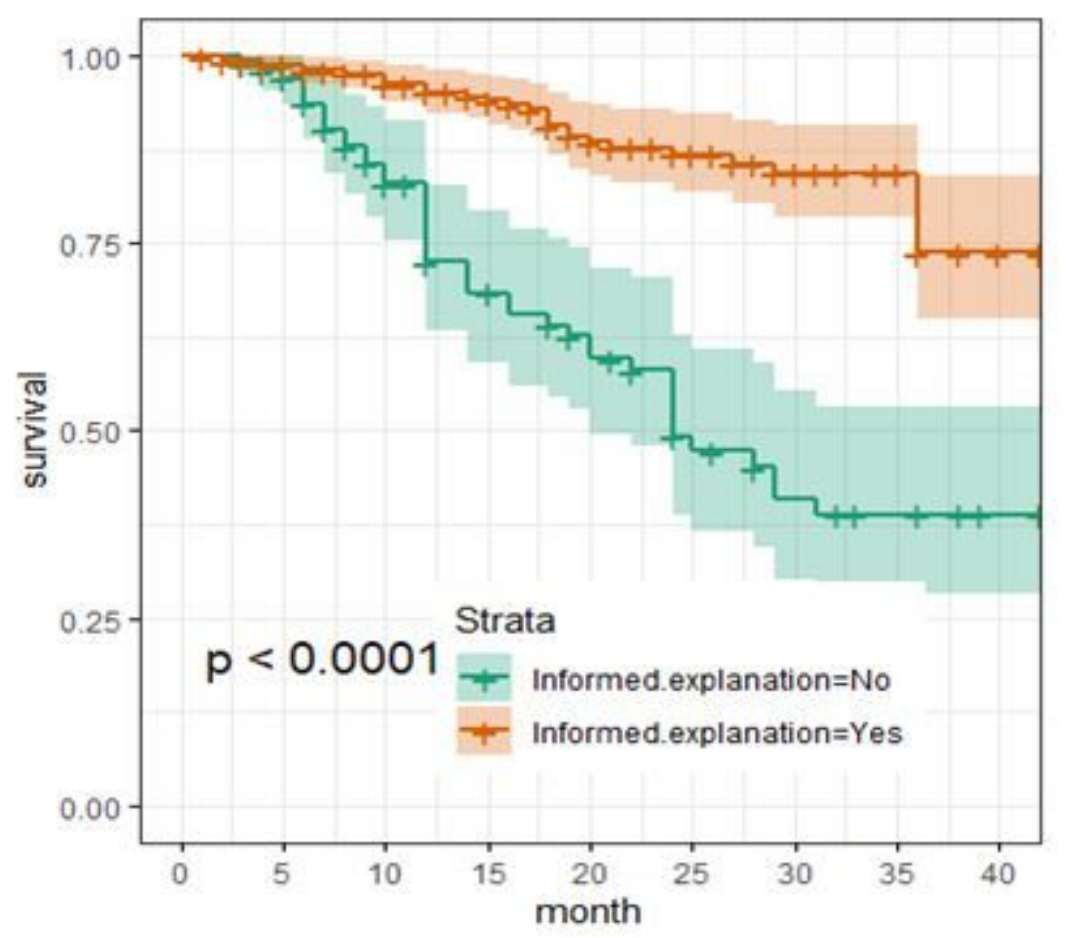

Figure 4

MCM drop out by lack of pre-MCM counselling

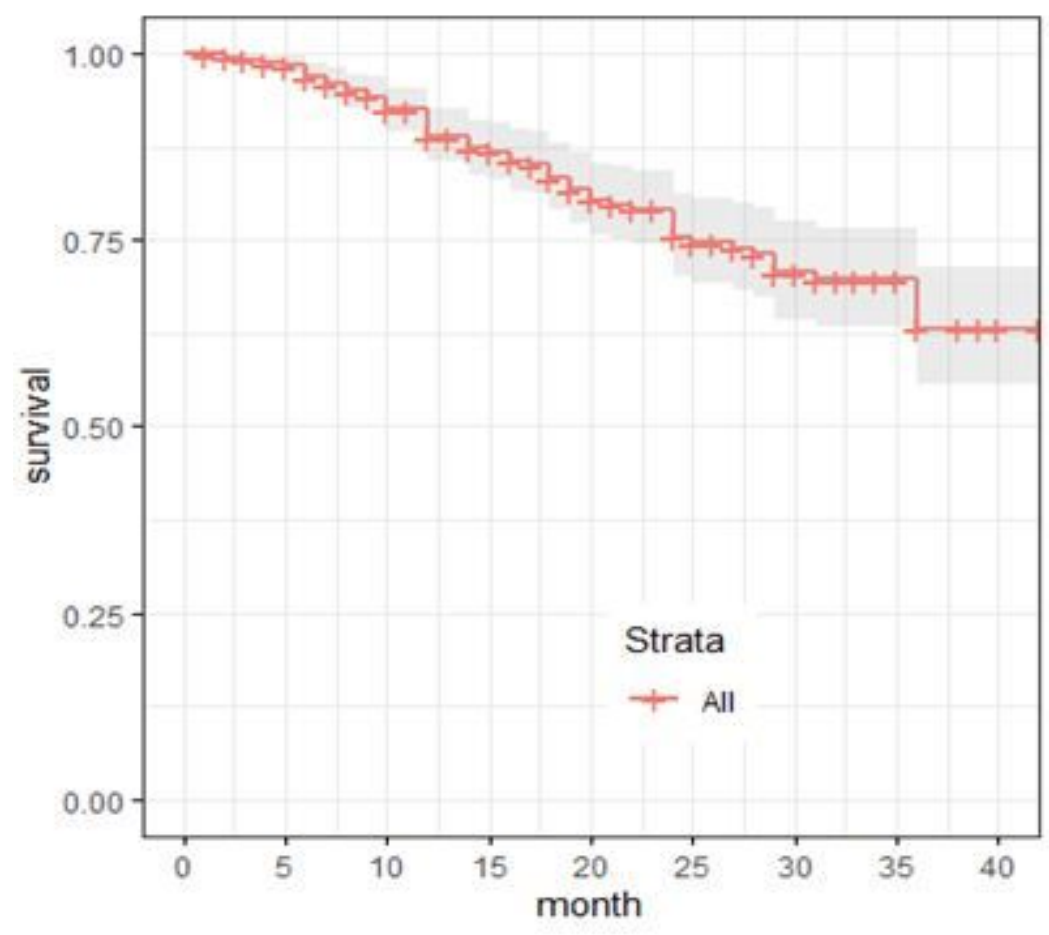

Figure 5

Overall MCM drop out 


\section{Supplementary Files}

This is a list of supplementary files associated with this preprint. Click to download.

- CONSENTfrancaisfinalversion.docx 